\title{
Propostes experimentals per entendre i compro- var el Principi de Pascal
}

\author{
Ernest Arnau Marco (adjunts@gmail.com) IES Quartó de Portmany (St. Antoni de Portmany - Eivissa)
}

Comprovació experimental del Principi de Pascal amb la construcció d'una premsa hidràulica $i$ una esfera de Pascal. En la part final de l'article compartim l'experiència del Barril de Pascal, visualitzem l'efecte d'una columna d'aigua i realitzem el càlcul de la pressió que fa rebentar un barril de vi.

Paraules clau: Principi de Pascal, esfera de Pascal, pressió, Barril de Pascal, premsa hidràulica.

Experimental verification of Pascal's principle by the construction of a hydraulic clamp and Pascal's sphere. Pascal's barrel experiment is developed in the final part of the article, analyzing the effect of a water column and calculating the pressure that makes the wine barrel burst.

Key words: Pascal's principle, Pascal's sphere, pressure, Pascal's barrel, hydraulic clamp.

\section{ÓBJ ECTIU}

El nostre objectiu és presentar el Principi de Pascal d'una forma intuïtiva per després aconseguir aprofundir en la seva comprensió amb l'ajuda de diferents experiències. Per aconseguir-ho construirem amb materials casolans:

- Una esfera de Pascal; també anomenada xeringa de Pascal.

- Una premsa hidràulica molt simple amb dues xeringues i un tub.

A més, explicarem i farem càlculs sobre el barril de Pascal.

\section{INTRODUCCIÓ}

Blaise Pascal (1623-1662) va contribuir a l'avanç científic de diverses rames del coneixement: teoria de la probabilitat, fluids, filosofia, la Pascalina... En aquest article ens centrarem en la seva contribució al camp dels fluids a través del Teorema de Pascal.
Inicialment el Teorema de Pascal[1] fou enunciat de forma empírica; per això comunament es coneix com a Principi de Pascal (nom que utilitzarem a partir del següent punt). Actualment es pot demostrar, motiu pel qual, alguns llibres el nombren com a Teorema (Burbano, 2003) en lloc de Principi: " La pressió exercida en un punt d'un líquid es transmet íntegrament a tots els seus punts."

Aquest teorema d'aspecte simple té multitud d'aplicacions en la vida quotidiana a través, entre altres, de les premses hidràuliques. Per aquest motiu considerem que és fonamental que els nostres alumnes el tinguin ben assolit; objectiu que s'aconsegueix amb l'experimentació.

\section{Idea intuïtiva de pressió}

Els nostres alumnes podran tenir una idea intuïtiva de la pressió a partir d'un experiment molt simple. Per a realitzar-lo necessitarem xinxetes i un guant de goma o globus, Figura 1. 

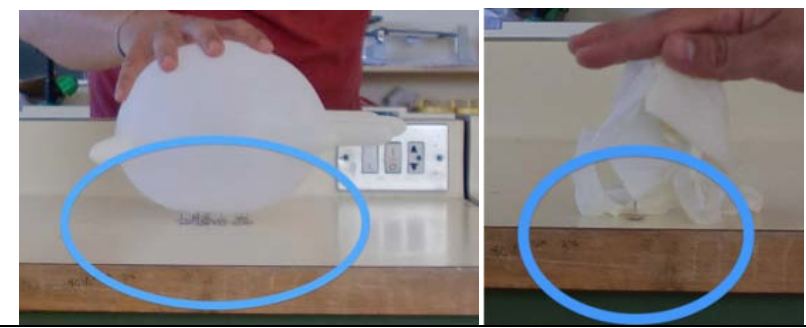

Figura 1. Visualització de la dependència de la pressió amb l'àrea. A la imatge de l'esquerra el guant de làtex està en contacte amb 15 xinxetes. A la dreta podem veure el globus després del contacte amb una sola xinxeta.

És senzill raonar que quantes més xinxetes introduïm major és l'àrea de contacte amb el globus $i$ que per a fer-lo explotar s'ha de realitzar major força. Per tant, observem que hi ha una relació entre la força i l'àrea:

$$
\text { Pressió }=\frac{\text { Força }}{\text { Àrea }}
$$

Podem utilitzar aquest moment per explicar:

- Per quin motiu afilem els ganivets.

- L'ús de raquetes i esquis al caminar per sobre la neu.

- Com els faquirs poden gitar-se sobre un llit de claus.

\section{La premsa hidràulica}

El primer que hem d'aconseguir és que els nostres alumnes tinguin una comprensió profunda del funcionament d'una premsa hidràulica. Per aconseguir-ho construirem dos tipus de premsa hidràulica d'igual aspecte però amb xeringues de diferent material (plàstic i vidre). Aquest experiment amb xeringues el podem trobar a diferents llibres de text de forma teòrica, per exemple a la pàgina 112 del llibre de text (Bruño, 1995)

Les parts fonamentals d'una premsa hidràulica són dos èmbols d'àrea diferents comunicats entre si. Pel principi de Pascal sabem que la pressió ha de ser igual en els dos pistons.

$$
p_{1}=p_{2} \stackrel{(1)}{\longrightarrow} \frac{F_{1}}{A_{1}}=\frac{F_{2}}{A_{2}}
$$

Com ja hem dit anteriorment l'única forma d'entendre realment un fenomen és tocar-lo, jugar amb ell i manipular-lo. Per això hem de permetre que els nostres alumnes experimenten amb una premsa hidràulica. Utilitzarem xeringues de plàstic de baix cost i disponibles a qualsevol farmàcia.
Després de comprar un parell de xeringues amb pistons de diferent àrea, les unirem amb un tub de goma dels que podem trobar a qualsevol laboratori i emplenarem l'interior amb aigua. Figura 2 En pocs minuts els nostres alumnes comprovaran les implicacions pràctiques de l'equació (2). Per exemple, veuran que el company amb la xeringa d'àrea petita és capaç de mantenir l'èmbol baix amb un sol dit per més esforços que exerceixin en l'altre èmbol.

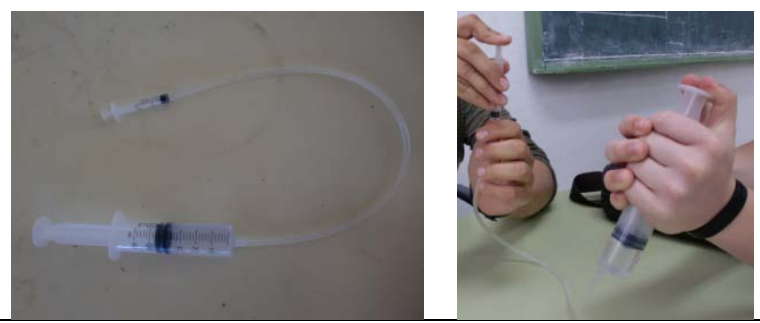

Figura 2. Esquerra: premsa hidràulica amb dues xeringues de diferent àrea. Dreta: experimentació de l'equació (2) amb un sol dit es pot mantenir l'èmbol de la xeringa petita en resposta a l'enorme força que realitza l'alumne amb la xeringa grossa.

Un cop entesa la base de la premsa hidràulica és el moment de fer comprovacions i prediccions. Per realitzar mesures no podem utilitzar èmbols de plàstics per la seva alta fricció. En aquest cas substituirem les xeringues de plàstic per unes de vidre. Aquestes xeringues són molt més fràgils (i cares) que les anteriors.

Si volem que els nostres alumnes es comporten com a vertaders científics hem de deixar que s'enfronten als reptes. La nostra tasca és fer de guia i com a tal hem de començar amb un objectiu per després deixar que investiguen en grups (0 sols). La nostra pregunta serà: si col-loquem una pesa de, per exemple, $500 \mathrm{~g}$, sobre de la xeringa grossa quina massa hem de col-locar en la petita per a què es mantingui?

Per donar una resposta els alumnes s'enfrontaran a diversos problemes: quina és l'àrea de les xeringues? Com calculem el radi? Quina és la força que realitzem? Com pot influir la fricció en la xeringa? I la dilatació del tub?

$$
\left.\begin{array}{l}
\operatorname{radi}_{\text {xeninga grossa }}=0,014 \mathrm{~m} \\
\operatorname{radi}_{\text {xeninga petita }}=0,006 \mathrm{~m} \\
\mathrm{~m}_{1}=0,5 \mathrm{~kg} \rightarrow F_{1}=4,9 \mathrm{~N}
\end{array}\right\} \rightarrow \frac{F_{1}}{A_{1}}=\frac{F_{2}}{A_{2}} \rightarrow
$$


$\rightarrow F_{2}=\frac{A_{2}}{A_{1}} \cdot F_{1}=\frac{\pi \cdot(0,006)^{2}}{\pi \cdot(0,014)^{2}} 4,9=0,9 \mathrm{~N} \rightarrow m_{2}=\frac{F_{2}}{9,8}=0,092 \mathrm{~kg}$

Òbviament després de colllocar aquesta peça podem fer canvis de massa i de xeringa per aprofundir en el coneixement. Veure el material a la figura 3.

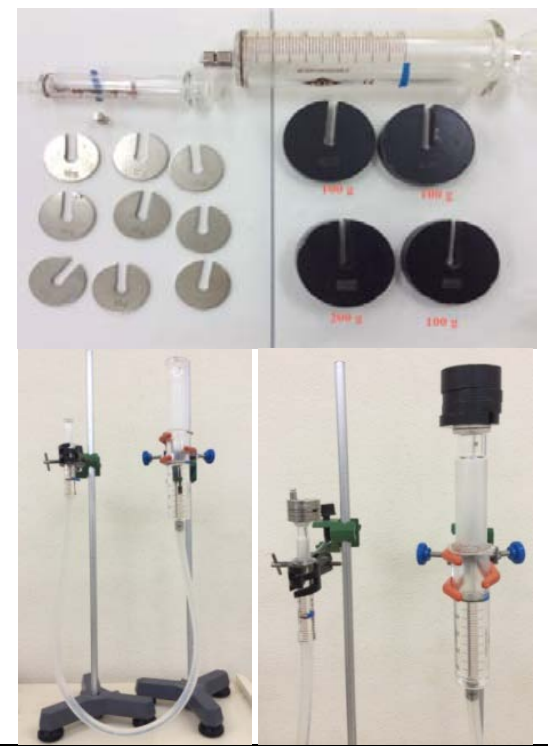

Figura 3. Esquerra, mostra del muntatge de les xeringues unides per un tub. Centre, peces que col-locarem en cada èmbol per mantenir la posició inicial. Dreta, col-locació de les peces en cada xeringa per comprovar el resultat deduït en (3)

\section{Fabricació d'una esfera de Pascal}

L'esfera de Pascal és un dispositiu que ens permet comprovar el principi de Pascal. Consisteix en un èmbol unit a una cavitat esfèrica a la qual es fan una sèrie de forats. Al temps de fer la demostració es plena l'esfera d'aigua i es procedeix a augmentar la pressió amb l'èmbol. La finalitat és observar que l'aigua surt per tots els orificis amb idèntica velocitat, comprovant així que la pressió que hem exercit s'ha transmet amb igual intensitat a totes les direccions i punts del fluid.

La nostra esfera de Pascal serà una modificació de la descrita anteriorment. Necessitarem: una xeringa grossa i algunes de petites, un tap, un tub de goma, cola per a plàstics i una ampolla d'esprai de plàstic de forma esfèrica (podem trobar-la a moltes botiges de tot a un euro).
La fabricació és extremadament simple, a l'ampolla d'esprai realitzem els forats del tamany de l'extrem de les xeringues petites (podem utilitzar un filferro calent). A continuació introduïm l'extrem de la xeringa i unirem amb cola. A la part superior cercarem un tap que ajusti a l'obertura, que unirem a la xeringa grossa amb un tub de vidre i un tub de goma. Figura 4

Un cop construïda la nostra esfera de Pascal sols hem d'emplenar-la d'aigua i amb l'èmbol de la xeringa augmentar la pressió. Quan realitzem l'experiment amb cura observarem que totes les xeringues petites recorren el mateix espai, fet que ens permet comprovar el Principi de Pascal. Figura 4.

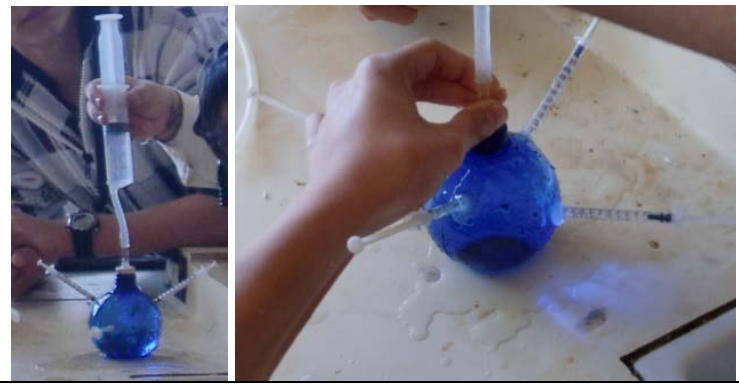

Figura 4. Esfera de Pascal fabricada amb materials casolans. A la imatge de l'esquerra podem observar les xeringues després de moure l'èmbol i comprovar el Principi de Pascal; totes desplaçades igual longitud

\section{El barril de Pascal}

Una part de l'encant de la ciència és la sorpresa contínua; algunes experiències encanten als científics i no arriben al públic en general però d'altres (com és el cas) poden meravellar a qualsevol. En aquesta part presentem una experiència que realitzà Pascal davant un nombrós públic.

Es pot rompre un barril de vi amb un litre d'aigua? Imaginem a un home en la part superior d'una escala rodejat de persones, en la base de dita escala hi ha un barril de vi ple d'aigua. De la seva part superior del barril i segellat hermèticament surt un tub de 12 metres d'altura fins la mà del nostre protagonista que sosté amb l'altra una gerra amb aigua. Poc a poc va omplint el tub fins que davant l'estupor general el barril rebenta.

Abans de fer càlculs hem de visualitzar l'experiència feta per Pascal; amb la nostra esfera de Pascal disposem d'una ferramenta per explicar visualment aquest cas. En Iloc de tapar l'esfera 
amb una xeringa grossa ho farem amb un tap de goma unit a un tub de vidre (1 metre de llargària). Després d'utilitzar les xeringues de goma i de vidre en la premsa hidràulica els alumnes coneixen la gran fricció que hi ha en les de goma. Per tant, els nostres alumnes saben, de forma intuïtiva, l'enorme pressió que ha de realitzar l'aigua per a moure un èmbol de plàstic. Veure figura 5

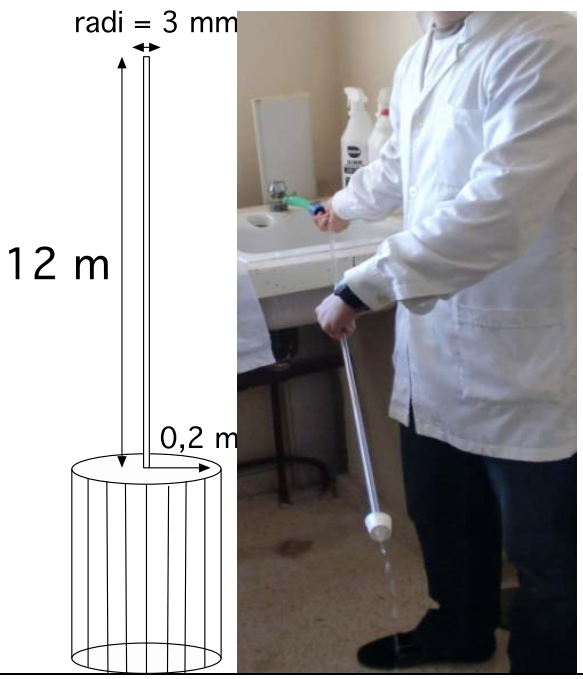

Figura 5. Esquema del Barril de Pascal amb els seus valors segons el problema 31 de la pàgina 386 [Tipler, 2004]. A la dreta visualització de l'efecte d'una columna d'aigua d'un metre sobre les xeringues de la nostra esfera de Pascal.

Podem fer alguns càlculs de la pressió i la força sobre la tapa del barril produïda per la columna de 12 metres d'aigua. (Figura 5)

$$
\begin{aligned}
P & =\frac{F}{S}=\frac{m g}{S}=\frac{\rho \cdot V \cdot g}{S}=\frac{\rho \cdot S \cdot h \cdot g}{S}=\rho \cdot h \cdot g= \\
& =1000 \frac{\mathrm{kg}}{\mathrm{m}^{3}} \cdot 12 \mathrm{~m} \cdot 9,8 \frac{\mathrm{m}}{\mathrm{s}^{2}}=117600 \frac{\mathrm{N}}{\mathrm{m}^{2}}
\end{aligned}
$$

La força sobre la tapa:

$$
\begin{gathered}
P=\frac{F}{S} \rightarrow F=P \cdot S= \\
=117600 \cdot \pi \cdot(0,2)^{2}=14778,1 N
\end{gathered}
$$

Que seria com col·locar una massa de $1.508 \mathrm{~kg}$ sobre el barril!

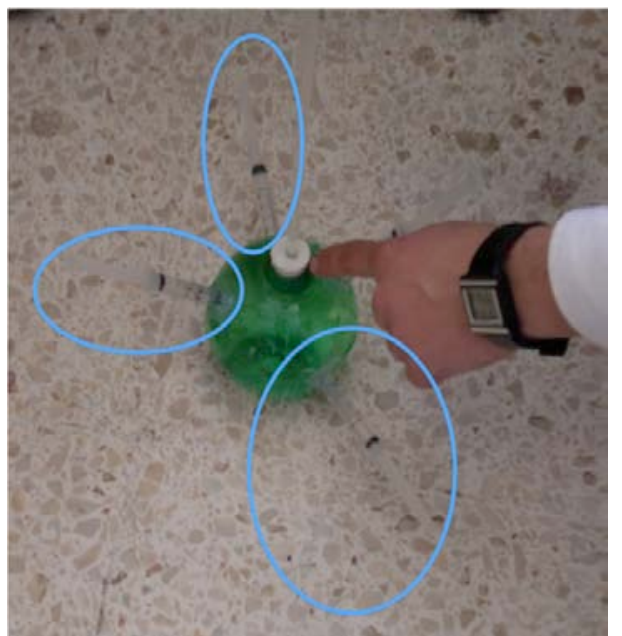

Figura 6. Observem que un altra volta comprovem el principi de Pascal al veure com les xeringues es desplacen igual distància

\section{BIBLIOGRAFIA I REFERÈNCIES}

BURBANO, S.; BURBANO, E.; GRACIA, C. (2003). Física General. Edició 32a . Madrid: Editorial Tébar, S. L. 800 págs

CRUZ LEÓN, A; CASTELLANO OLMEDO, E (1995). Ciencias de la Naturaleza: Física y Química 4 ESO. Madrid: Editorial Bruño. 192 págs.

TIPLER, P., MOSCA, G. (2004). Física para la ciència y la tecnologia: Mecánica. Oscilaciones y ondas. Termodinámica: 1. Edició 5a ${ }^{a}$. Barcelona: Editorial Reverté. 660 págs

[1] No confondre amb el Hexagrammum Mysticum Theorema de la geometria projectiva.

Especial agraïment a Mariano Bericat, professor de Física i Química de l'IES Quartó de Portmany, per ser guia i base en la metodologia i experiments proposats en el present article. 